\title{
Effect of Maturation Time of Coagulum of Fresh Natural Rubber Latex on Oxidation Kinetics of Natural Rubber
}

\author{
Zhang Bei-long ${ }^{\mathrm{a}}$, Huang Hong-hai ${ }^{\mathrm{b}}$, Wang Yong-zhou ${ }^{\mathrm{c}}$, Ding $\mathrm{Li}^{\mathrm{d}}$, Wang \\ Ping-yue ${ }^{\mathrm{e}}$ \\ Ministry of Agriculture Key Laboratory of Tropical Crops Processing, Agricultural Product \\ Processing Research Institute, Chinese Academy of Tropical Agricultural Sciences, P. O. Box 318, \\ Zhanjiang 524001, P.R. China; \\ Email: agdzjlong2013@163.com, 'bhonghaihuang2009@163.com, cwyz011120@163.com, \\ dgdzjding@hotmail.com, "wangpy2006@aliyun.com
}

Keywords: natural rubber, fresh natural rubber latex, coagulation, maturation time, oxidation kinetics

\begin{abstract}
The oxidation kinetics of natural rubbers prepared by coagulum of fresh natural latex coagulated with formic acid or microorganisms were studied. The maturation time of coagulum is 6 , 12, 18 and 24 hours respectively. The results show that the oxidation activation energies of natural rubbers prepared with two coagulation methods increase with increasing maturation time. The oxidation activation energy of natural rubber coagulated with microorganisms is greater than that of natural rubber coagulated with formic acid, but the increment of oxidation activation energy with the increase in maturation time of coagulum of natural rubber coagulated with formic acid is greater than that of natural rubber coagulated with microorganisms.
\end{abstract}

\section{Introduction}

Natural rubber is prepared through coagulating, maturation, creping, size reduction and drying of the latex from Hevca Brasiliensis(rubber trees). The above each process step will bring about great effect[1] on the property of natural rubber. The microbial-coagulation, acid-coagulation and natural-coagulation are commonly-used three main methods to coagulate fresh natural rubber latex. The coagulation speed of fresh natural rubber latex coagulated with acid is fast, but the production post of acid-coagulation is higher. The fresh natural rubber latex coagulated with acid will damage some beneficial components in natural rubber latex, which will affect the performance of natural rubber. The environment will be polluted by wastewater produced during process. The production post of fresh natural rubber latex coagulated with natural-coagulation is lower, and the quality of product is better but longer time is needed to coagulation. There are some reports [2][3][4] on fresh natural rubber latex coagulated with microbial, however, no paper is available about application of microbial-coagulation in production. The coagulation rate of fresh natural rubber latex coagulated with microbial-coagulation technology is faster, the production cost is relative lower, the product quality is relative better, and the environment pollution is reduced[5].The maturation time of coagulum of fresh natural rubber latex can affect the property of natural rubber. The studies[6][7][8] show that the nitrogen content of natural rubber prepared with microbial-coagulation decrease, $\mathrm{P}_{0}$ and Mooney viscosity increase, plasticity retention index(PRI)changes a little, curing rate becomes fast, and tensile strength of vulcanizate increases first then decreases, with prolongation of maturation time of coagulum. Since the nitrogen content decreases with prolongation of maturation time of coagulum, other non-rubber compositions will also change. The change in non-rubber compositions can affect mechanical properties, heating built-up and aging property of vulcanizate. The maturation time of coagulum is generally 12-18 hours in production, and will be increased to 24hours in some case. It is necessary to research the change of properties of natural rubber during maturation of coagulum, however, no paper is available about the effect of maturation time on oxidation aging- resistance of natural rubber. The authors of this article researched the oxidation kinetics of natural rubber prepared by coagulum coagulated with microbial-coagulation or 
acid-coagulation and maturated for difference time, and obtained satisfactory results.

\section{Materials}

Fresh natural rubber latex was obtained from Fenyong Farm in Guangdong Province.

Formic acid was of chemical grade.

Microbial coagulator was a type of microorganism strains that was added into 5\% molasses solution for inoculation of 24hours.

\section{Formic acid coagulation}

Fresh natural rubber latex containing 0.04\%ammonia was coagulated with formic acid. The level of formic acid was $0.4 \%$ of weight of dry rubber in fresh natural rubber latex, then the formic acid was diluted to $5 \%$ for use (the other calculation should be make for the formic acid needed to neutralize the ammonia in fresh natural rubber latex.) The coagulum was take out 6 hours,12hours,18hours or 24 hours after formic acid solution was put into fresh natural rubber latex, then was creped, size-reduced and dried at $115^{\circ} \mathrm{C}$ for 5 hours in an oven.

\section{Microbial coagulation}

The level of microbial coagulator was calculated according to a ratio of $2 \mathrm{~g}$ molasses $/ 100 \mathrm{~g}$ dry rubber in fresh natural rubber latex .The fresh natural rubber latex was fully stirred immediately after microbial coagulator was put into the latex, and was quiescent stand for coagulation. The coagulum was take out 6 hours,12hours,18hours or 24 hours after microbial coagulator was put into fresh natural rubber latex, then was creped, size-reduced and dried at $115^{\circ} \mathrm{C}$ for 5 hours in an oven.

\section{Test}

A Differential Scanning Calorimeter DSC-220 (Seiko Instruments Inc) was used. The temperature rising rate was $4,5,6,8$ and $10^{\circ} \mathrm{C} / \mathrm{min}$, respectively. The air flow rate (atmosphere) was $50 \mathrm{~mL} / \mathrm{min}$.

\section{Test results}

Natural rubber will oxidize slowly in environment temperature, and the oxidation will become faster in hot air (hot oxygen) environment. The hot oxidation aging resistance of natural rubber is closely relative to thermal oxidation kinetics. It is difficult to obtain oxidation data of natural rubber at room temperature. Natural rubber will oxidize in a shorter time through heating, and the oxidation temperature of natural rubber during heating can be acknowledged. The information of oxidation of natural rubber can be obtained through analysis of these data with thermal kinetics equation. Zhang Bei-long et al.[9] have conformed that the first exothermal peak of natural rubber at $185 \sim 205^{\circ} \mathrm{C}$ under air atmosphere is the oxidation exothermal peak of natural rubber with a method of TG-DTA . The DSC was used to obtain the temperature of oxidation exothermal peak of constant viscosity natural rubber accurately in this study, and the oxidation activation energy of constant viscosity natural rubber can be obtained according to Doyle-Ozawa equation[10] as follows

$$
\frac{d \log \beta}{d\left(1 / T_{p}\right)}=\frac{-0.4567 E}{R}
$$

The equation (1) can be also written as

$$
\log \beta=\frac{-0.4567 E}{R} \bullet \frac{1}{T_{p}}+C
$$

where $\beta$ is heating rate $\left(\mathrm{K} / \mathrm{min}\right.$ or $\left.{ }^{\circ} \mathrm{C} / \mathrm{min}\right)$, Tp is the largest peak temperature $(\mathrm{K})$ of the first 
oxidative exothermal peak, $\mathrm{R}$ is the gas constant $(R=8.314)$, and $\mathrm{C}$ is a constant. When a diagram is plotted with $\log \beta$ and $1 / T p$ as coordinates, a straight line is obtained by the use of least square regression method, the slope of the straight line is $-0.4567 / R$; from this, the value of the activation energy of constant viscosity natural rubber can be calculated out. $C$ is the intercept of the straight line.

\section{Effect of maturation time of coagulum coagulated with formic acid on oxidation kinetics of natural rubber}

Figure 1-4 are DSC curves of raw natural rubber prepared by coagulum maturated for 6 hours, 12 hours, 18 hours and 24 hours respectively. The fresh natural rubber latex was coagulated with formic acid. The largest peak temperatures of the first oxidative exothermal peaks of test samples in temperature rising rate of 4,5,6,8 and $10^{\circ} \mathrm{C} / \mathrm{min}$, respectively, and the thermal oxidation activation energies of samples calculated according to Doyle-Ozawa equation are list in Table 1. It can be seen from Figure1- 4 and data in Table1 that the oxidation exothermal peaks of the test samples appear at the range of $190 \sim 210^{\circ} \mathrm{C}$.The temperature of exothermal peak moves to higher temperature with increasing heating rate. The oxidation activation energy of samples calculated according to Doyle-Ozawa equation increases from $105.5 \mathrm{~kJ} / \mathrm{mol}$ of coagulum maturated for 6 hours to $118.9 \mathrm{~kJ} / \mathrm{mol}$ of coagulum maturated for 24 hours with prolongation of the maturation time.

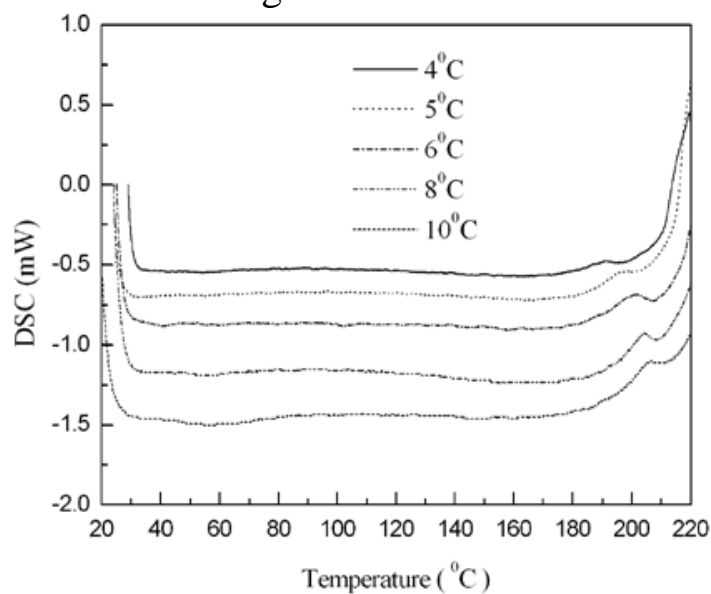

Figure 1 DSC curve of natural rubber prepared with formic acid coagulation and maturated for 6 hours

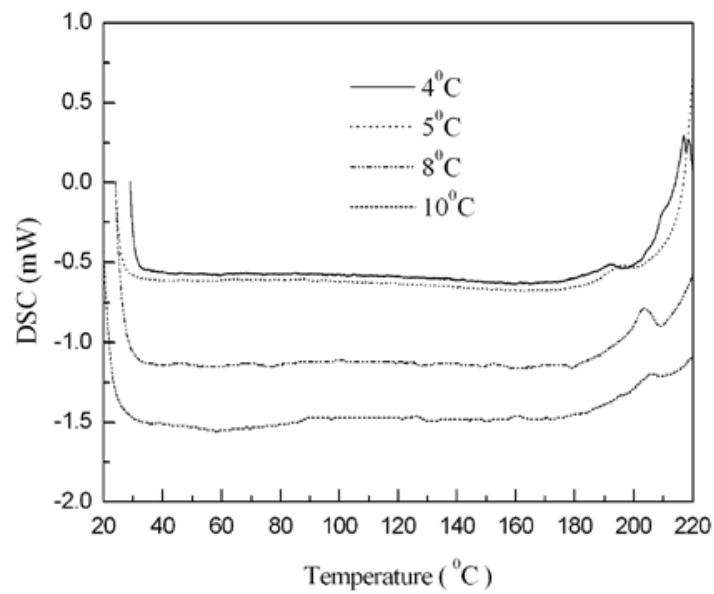

Figure 3 DSC curve of natural rubber prepared with formic acid coagulation and maturated for 18 hours

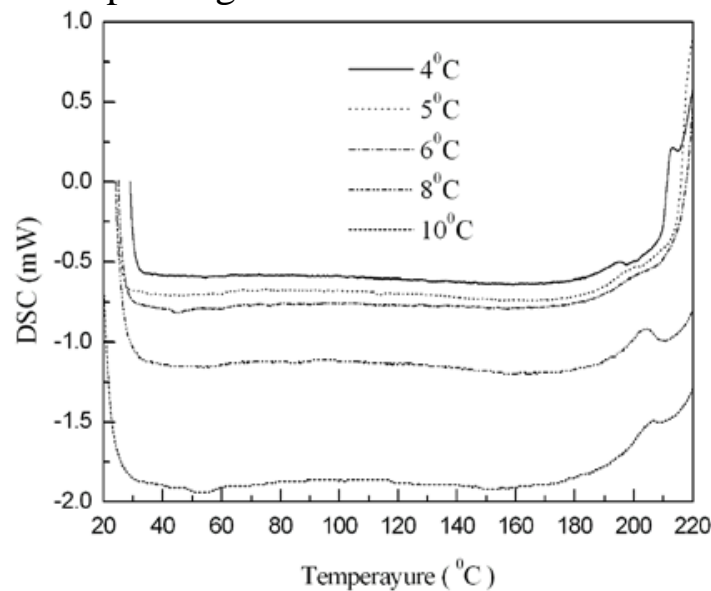

Figure 2 DSC curve of natural rubber prepared with formic acid coagulation and maturated for 12 hours

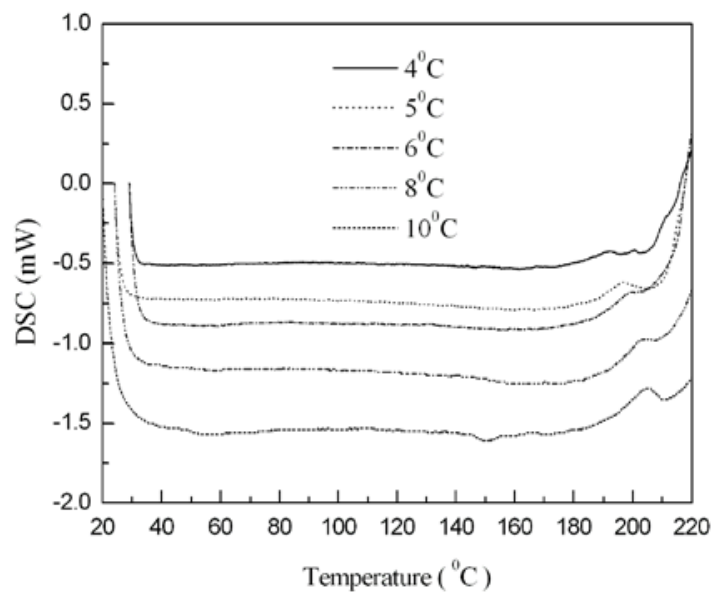

Figure 4 DSC curve of natural rubber prepared with formic acid coagulation and maturated for 24 hours 
Table 1 the largest peak temperature of oxidation exothermal peak and the activation energy of natural rubber prepared with formic acid coagulation

\begin{tabular}{|c|c|c|c|c|c|c|c|}
\hline \multirow{3}{*}{$\begin{array}{l}\text { maturation } \\
\text { time }\end{array}$} & \multicolumn{5}{|c|}{ heating rate $\left({ }^{\circ} \mathrm{C} / \mathrm{min}\right)$} & \multirow{3}{*}{$\begin{array}{c}\text { activation } \\
\text { energy } \\
(\mathrm{kJ} / \mathrm{mol})\end{array}$} & \multirow{3}{*}{$\begin{array}{l}\text { correlation } \\
\text { coefficient }\end{array}$} \\
\hline & 4 & 5 & 6 & 8 & 10 & & \\
\hline & \multicolumn{5}{|c|}{$\begin{array}{l}\text { the largest peak temperature of oxidation exothermal peak } \\
\mathrm{T}_{\mathrm{p}}\left({ }^{\circ} \mathrm{C}\right)\end{array}$} & & \\
\hline $6 \mathrm{~h}$ & 191.92 & 196.65 & 201.78 & 204.30 & 206.49 & 105.5 & 0.9701 \\
\hline $12 \mathrm{~h}$ & 194.63 & 196.70 & 203.89 & 204.69 & 206.97 & 113.1 & 0.9404 \\
\hline $18 \mathrm{~h}$ & 192.63 & 196.16 & & 203.26 & 206.70 & 115.0 & 0.9999 \\
\hline $24 \mathrm{~h}$ & 192.31 & 196.66 & 199.96 & 203.99 & 205.21 & 118.9 & 0.9820 \\
\hline
\end{tabular}

\section{Effect of maturation time of coagulum coagulated with microbial on oxidation kinetics of natural rubber}

Figure 5-8 are DSC curves of raw natural rubber prepared by coagulum maturated for 6 hours, 12 hours, 18 hours and 24 hours respectively. The fresh natural rubber latex was coagulated with microbial. The largest peak temperatures of the first oxidative exothermal peaks of test samples in temperature rising rate of $4,5,6,8$ and $10^{\circ} \mathrm{C} / \mathrm{min}$, respectively, and the thermal oxidation activation energies of samples calculated according to Doyle-Ozawa equation are list in Table 2. It can be seen from Figure 5- 8 and data in Table 2 that the oxidation exothermal peaks of the test samples appear at the range of $190 \sim 210^{\circ} \mathrm{C}$ (the temperature of exothermal peak moves to higher temperature with increasing heating rate), as the same as that of the samples coagulated with formic acid. The oxidation activation energy of samples calculated according to Doyle-Ozawa equation increases from $125.4 \mathrm{~kJ} / \mathrm{mol}$ of coagulum maturated for 6 hours to $136.3 \mathrm{~kJ} / \mathrm{mol}$ of coagulum maturated for 24 hours with prolongation of the maturation time.

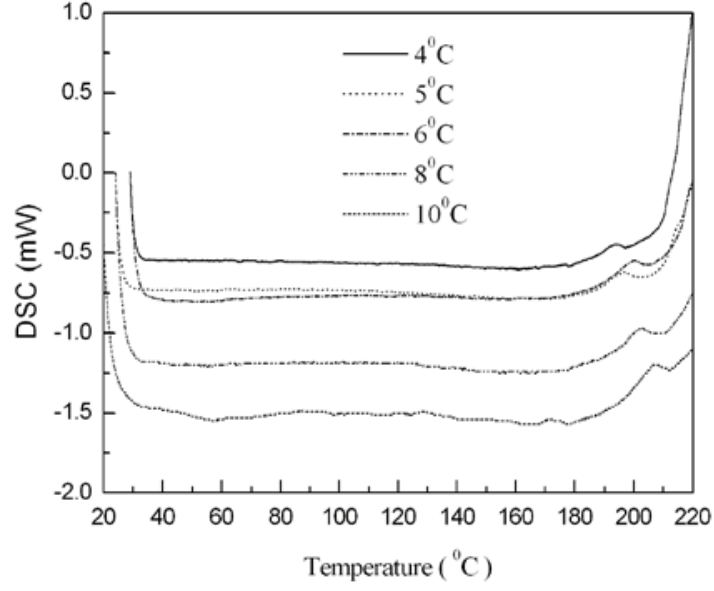

Figure 5 DSC curve of natural rubber prepared with microbial coagulation and maturated for 6 hours

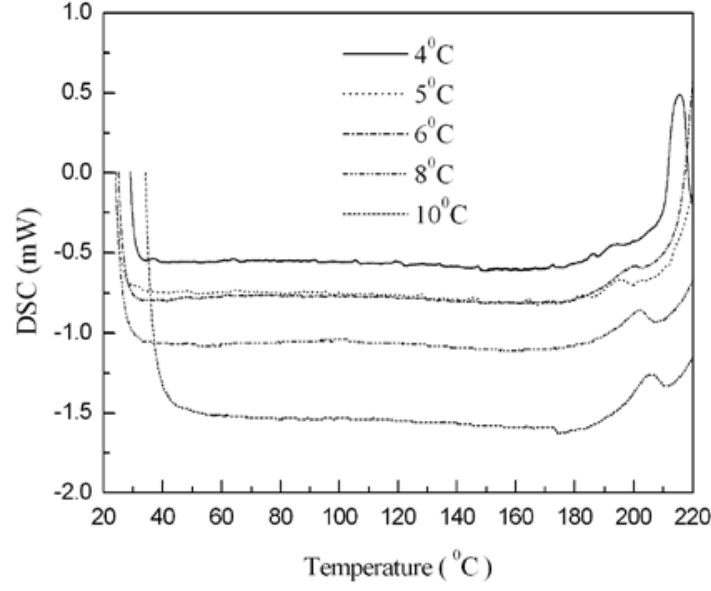

Figure 6 DSC curve of natural rubber prepared with microbial coagulation and maturated for 12 hours 


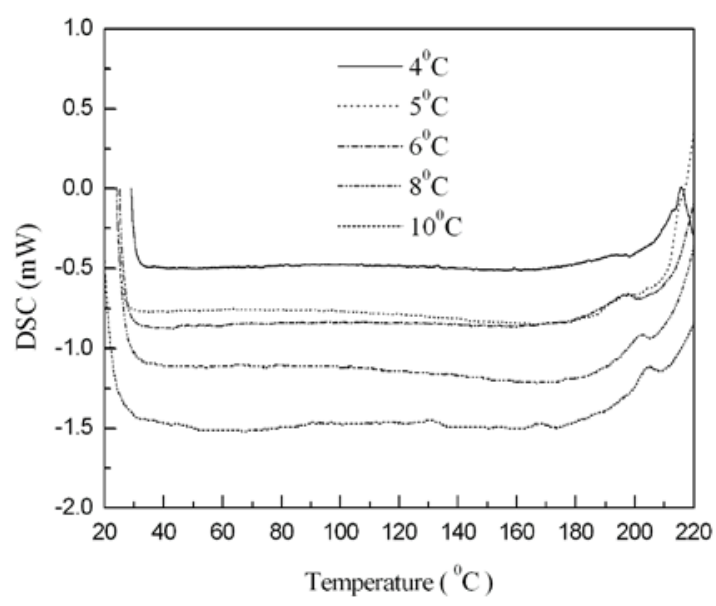

Figure 7 DSC curve of natural rubber prepared with microbial coagulation and maturated for 18hours

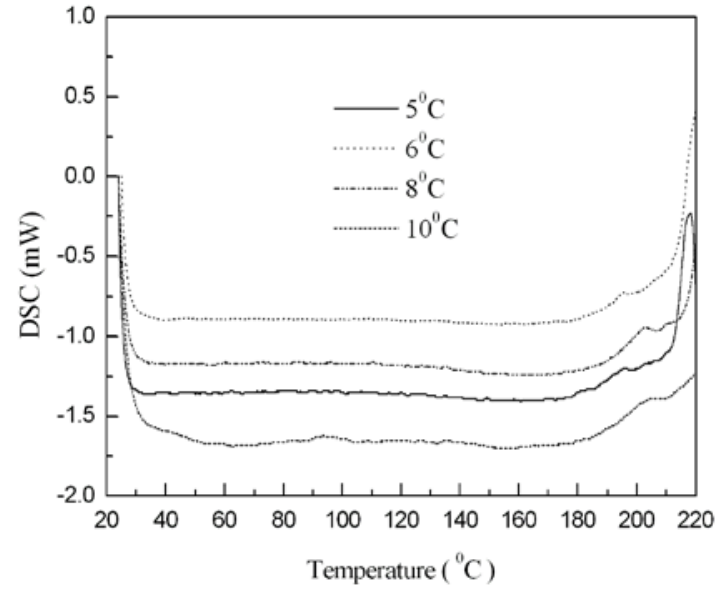

Figure 8 DSC curve of natural rubber prepared with microbial coagulation and maturated for 24hours

\section{Difference between oxidation kinetics of natural rubber prepared with formic acid and oxidation kinetics of natural rubber prepared with microbial}

Table 2 the largest peak temperature of oxidation exothermal peak and the activation energy of natural rubber prepared with microbial coagulation

\begin{tabular}{|c|c|c|c|c|c|c|c|}
\hline \multirow{3}{*}{$\begin{array}{l}\text { maturation } \\
\text { time }\end{array}$} & \multicolumn{5}{|c|}{ heating rate $\left({ }^{\circ} \mathrm{C} / \mathrm{min}\right)$} & \multirow{3}{*}{$\begin{array}{c}\text { activation } \\
\text { energy } \\
(\mathrm{kJ} / \mathrm{mol})\end{array}$} & \multirow{3}{*}{$\begin{array}{l}\text { correlation } \\
\text { coefficient }\end{array}$} \\
\hline & 4 & 5 & 6 & 8 & 10 & & \\
\hline & $\begin{array}{l}\text { the largest } \\
\text { peak } \mathrm{T}_{\mathrm{p}}\left({ }^{\circ} \mathrm{C}\right)\end{array}$ & peak $t$ & erature & oxidation & xothermal & & \\
\hline $6 \mathrm{~h}$ & 194.00 & 196.78 & 200.60 & 202.75 & 207.11 & 125.4 & 0.9907 \\
\hline $12 \mathrm{~h}$ & 193.72 & 195.52 & 200.10 & 202.01 & 205.75 & 130.2 & 0.9845 \\
\hline $18 \mathrm{~h}$ & 193.58 & 196.65 & 197.92 & 202.53 & 205.47 & 135.7 & 0.9961 \\
\hline $24 \mathrm{~h}$ & & 196.16 & 199.62 & 202.83 & 205.28 & 136.3 & 0.9915 \\
\hline
\end{tabular}

Figure 9 shows the change of oxidation activation energies of samples prepared with formic acid coagulation or microbial coagulation. The oxidation activation energies of natural rubber prepared with formic acid coagulation or microbial coagulation increase gradually with prolongation of maturation time. The oxidation activation energy of natural rubber prepared with microbial coagulation increases by $10.3 \mathrm{~kJ} / \mathrm{mol}$ when maturation time increases from 6 hours to 18 hours, and the growth of oxidation activation energy is $8.2 \%$. The oxidation activation energy of natural rubber prepared with formic acid increases by $9.5 \mathrm{~kJ} / \mathrm{mol}$ when maturation time increases from 6 hours to 18 hours, and the growth of oxidation activation energy is 9.0\%. The oxidation activation energy of natural rubber prepared with microbial coagulation increases by $10.9 \mathrm{~kJ} / \mathrm{mol}$ when maturation time increases from 6 hours to 24 hours, and the growth of oxidation activation energy is $8.7 \%$. The oxidation activation energy of natural rubber prepared with formic acid increases by $13.4 \mathrm{~kJ} / \mathrm{mol}$ when maturation time increases from 6 hours to 24 hours, and the growth of oxidation activation energy is $12.7 \%$. The oxidation activation energy of natural rubber prepared with formic acid is lower than that of natural rubber prepared with microbial coagulation, and the growth of oxidation activation energy with prolongation of maturation time is greater than that of natural rubber prepared with microbial coagulation. 


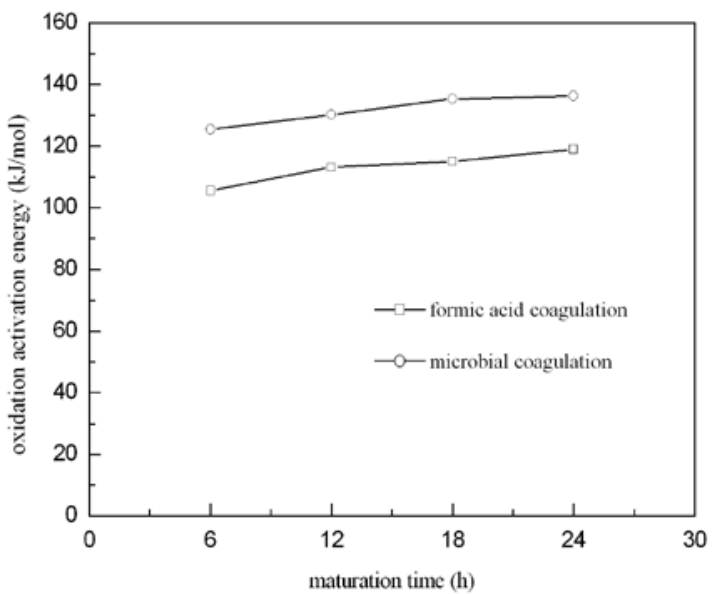

Figure 9 Changes of oxidation activation energies with maturation time for natural rubber prepared with the methods of formic acid coagulation and microbial coagulation

\section{Conclusion}

The oxidation activation energies of natural rubber prepared with formic acid coagulation and microbial coagulation increase gradually with prolongation of maturation time. The oxidation activation energy of natural rubber prepared with formic acid is lower than that of natural rubber prepared with microbial coagulation, and the growth of oxidation activation energy with prolongation of maturation time is greater than that of natural rubber prepared with microbial coagulation.

\section{Acknowledgements}

This work was supported by National Natural Science Foundation of P.R.China (Project No.50963006) and Provincial science and technology planning project of Guangdong (Project No.2015A020209012), is gratefully acknowledged.

\section{References}

[1] Yuan Z.C., Liu Y.D., Application Property of Raw Natural rubber and Natural Rubber Latex , Agriculture Press, Beijing, P100-103

[2] C.K.John,. Biological Coagulation of Hevea Latex Using Waste Carbohydrate Substrates. Journal of the Rubber Research Institute of Malaya. 1966, Vol.19(5): 286-289

[3] C.K.John, N.M.Pillai,. Improvements to Assisted Biological Coagulation of Hevea Latex. Journal of the Rubber Research Institute of Malaya. 1971,Vol23(2): 138-146

[4] Wang Zhong-ming, Yu Meng-jun,China Tropical Agricultural products Processing. 1998, No2: $1-5$

[5] Zhang Bei-long, Liu Pei-ming, Deng Wei-yong, Lu Heng-xiang, Ding Li, Wang Ping-yue, Wang Yong-zhou,. Properties of NR by Microorganisms. China Rubber Industry. 2012, Vol.59 (9): 553-558

[6] Huang Ke-fen, China Tropical Agricultural products Processing. 1997, No3/4: 7-9

Huang Ke-fen, China Tropical Agriculture Engineering. 1999, No3: 1-2

[7] Zhong Jie-ping,Yang Lei, Deng Wei-yong, Zhang Bei-long, China Rubber Industry, 2004, Vol.51(5): 284-285

[8] Bei-long Zhang, Wei-Yong Deng,. et.al., Study on Effective Storage Time of Raw [9]Natural 
Rubber, J. Appl. Polym. Sci., 2006, Vol.100: 4113-4119

[10] Lye P H, Toh H K. Study of Rubber Oxidation by Thermoanalysis., J. Appl. Polym. Sci., 1984, Vol.29: 2628 